INSTITUT NATIONAL DE LA STATISTIQUE ET DES ETUDES ECONOMIQUES

Série des Documents de Travail du CREST

(Centre de Recherche en Economie et Statistique)

$n^{\circ}$ 2010-13

A Simple Theory of Optimal Redistributive Taxation with Equilibrium Unemployment

\author{
M. HUNGERBÜHLER - E. LEHMANN \\ A. PARMENTIER - B. VAN DER LINDEN
}

Les documents de travail ne reflètent pas la position de l'INSEE et n'engagent que leurs auteurs.

Working papers do not reflect the position of INSEE but only the views of the authors. 


\title{
A Simple Theory of Optimal Redistributive Taxation with Equilibrium Unemployment*
}

\author{
Mathias HUNGERBÜHLER ${ }^{\dagger}$ \\ FUNDP - University of Namur \\ Etienne LEHMANN $\ddagger$ \\ CREST (INSEE) \\ Alexis PARMENTIER ${ }^{\S}$ \\ EPEE (TEPP) Université d'Evry \\ IRES - Université Catholique de Louvain \\ Bruno VAN DER LINDEN \\ IRES - Université Catholique de Louvain, FNRS, \\ ERMES - Université Paris 2
}

17th September 2010

\begin{abstract}
We consider an optimal nonlinear income tax problem in a model with searchmatching unemployment and where the negotiated pre-tax wage decreases with marginal tax rate but increases with the level of tax. By omitting labor supply responses and assuming benefit for the unemployed and an efficient allocation in the absence of tax, we characterize the optimal equity-efficiency trade off. We show that in labor market specific to each interior level of skill, optimal wages and unemployment rates are distorted downwards. Moreover, average tax rate are increasing along the income distribution and marginal tax rate are positive at the top, even when the skill distribution is bonded.
\end{abstract} ing

Keywords: Optimal Income Taxation, Unemployment, Wage Bargaining, Match-

JEL numbers: D82, H21, H24, J64

\footnotetext{
${ }^{*}$ This research has been funded by the Belgian Program on Interuniversity Poles of Attraction (P6/07 Economics Policy and Finance in the global economy: equilibrium analysis and social evaluation) initiated by the Belgian state, Prime Minister's office, Science Policy Programming. We thank Guy Laroque for his comments and suggestions.

${ }^{\dagger}$ E-mail: mathias.hungerbuhler@fundp.ac.be. Department of Economics, FUNDP Namur, Rempart de la Vièrge 8, 5000 Namur, Belgium.

${ }^{\ddagger}$ Etienne Lehmann is also an external member of IRES - Université Catholique de Louvain, and a research fellow of IZA and of IDEP. Adress: CREST-INSEE, 15 Boulevard Gabriel Péri 92245 Malakoff Cedex, France. email: etienne.lehmann@ensae.fr.

${ }^{\S}$ Adress: EPEE - Université d'Evry Val d'Essonne, 4 boulevard François Mitterand, 91025, Evry Cedex, France. Email: alexis.parmentier@univ-evry.fr

"Bruno Van der Linden is also research fellow at IZA. Address: IRES, Université Catholique de Louvain, Place Montesquieu 3, B1348, Louvain-la-Neuve, Belgium. Email: bruno.vanderlinden@uclouvain.be.
} 


\section{Introduction}

Since Mirrlees (1971), the theory of optimal income taxation considers the design of the optimal redistributive policy when the government cannot condition taxes on (exogenous) skills but only on (endogenous) earnings. The theory considers perfect frictionless labor markets, and ignores in particular the possible emergence of (involuntary) unemployment.1 However, many studies emphasize the deep impact of labor market taxation on employment (e.g. Prescott (2004), Rogerson (2006)) and more specifically on unemployment (Daveri and Tabellini (2000) and Nickell, Nunziata and Ochel (2005)). Moreover, unemployment, and not only low ability, is an important source of poverty. A more comprehensive theory of optimal redistribution should thus be developed in an environment where unemployment is a genuine phenomenon affected by taxation.

In labor market models that take unemployment into account, the level of employment is determined by labor demand, which is a decreasing function of the pre-tax wage. In a non-competitive wage-setting and when the intensive margin (the hours-of-work decision) of labor supply is omitted, a change in tax policy that increases the marginal tax rate without affecting the level of the tax reduces the pre-tax wage, thereby increasing labor demand and reducing unemployment. This is what we call the wage-cum-labor-demand margin. Intuitively, such a tax change induces that a given increase in the negotiated post-taxed wage is more costly for the employers. Consequently, they become more reluctant to concede workers' wage claims. On the contrary, a tax change that increases the level of tax while keeping the marginal tax rate unchanged increases labor cost, thereby unemployment. These properties have been demonstrated in various theoretical settings: the monopoly union model (Hersoug, 1984), the right-to manage union model (Lockwood and Manning, 1993), the matching model (Pissarides, 1998) and the efficiency wage model (Pisauro, 1991). Empirical evidence that suggests the importance of these effects has also been put forward in the literature (Manning (1993), Røed and Strøm (2002) or Sørensen (1997)). The effect of the marginal tax rate on pre-tax wages obtained in these model is also consistent with the empirical findings on the elasticity of income with respect to the marginal tax rate surveyed by Saez et alii (2009). According to them, the most plausible estimates for the elasticity of earnings to one minus the marginal tax rate range from 0.12 to 0.4 in the U.S. Whether this elasticity is due to a labor supply response (as in a Mirrleesian model) or to a non-competitive wage setting response has to our knowledge, not been investigated yet, and remains an open empirical issue.

Boone and Bovenberg (2004) separate unemployment from non-participation in an optimal redistributive taxation framework where the government does not observe the skill level of the agents. However the unemployment risk does not depend neither on wages nor

\footnotetext{
${ }^{1}$ Many international institutions (such as the ILO or the OECD) distinguish among non-employed individuals the unemployed who search for a job from those out-of-the-labor-force.
} 
on taxation in their model. Engström (2009) extends the Stiglitz (1982) two-skill model of optimal taxation by introducing search unemployment, but with exogenous hourly wages. Three recent papers (Hungerbühler et alii (2006, henceforth HLPV), Hungerbühler and Lehmann (2009, henceforth HL) and Lehmann et alii (2009, henceforth LPV)) propose a theory of optimal redistributive taxation with an endogenous risk of being unemployed. In these models, the deadweight losses of redistributive taxation are due to responses along the wage-cum-labor-demand margin and not along the intensive labor supply margin. The present article proposes a canonical model of optimal redistribution with unemployment. This model, which is exposed in the next section, aims at shedding light on the different mechanisms at work. We ignore participation decisions and welfare benefits, these simplifications being the main contribution of the present paper compared to HLPV, HL and LPV. This Section also emphasizes the methodological differences and analogies between our simple model and a version of the Mirrlees model that generates the same responses of pre-tax earnings to taxation. The concluding section discusses the influence of our simplifying assumptions on the results and spells out the relationship of our canonical model to HLPV, HL and LPV.

\section{The canonical model}

\section{II.1 Environment}

We consider an economy where risk-neutral individuals are endowed with different skill (ability) levels denoted $a$. The exogenous skill distribution is given by the continuous density function $f(a)$, defined on the support $\left[a_{0}, a_{1}\right]$, with $0<a_{0}<a_{1} \leq+\infty$. The size of the population is normalized to 1 . Jobs are skill-specific. A worker of skill $a$ produces $a$ units of output if and only if she is employed in a type- $a$ job, otherwise her production is nil. This assumption of perfect segmentation is made for tractability and seems more realistic than the polar one of a unique labor market for all skill levels.

The government observes only whether an individual is employed or not, and if she is, at which wage. The government in particular does not observe skills nor the recruiting processes. Hence, taxation is only a function of wages. A worker of skill $a$ gets a (pre-tax) wage $w_{a}$ and a disposable income $c_{a}=w_{a}-T\left(w_{a}\right)$ if she is employed. Otherwise, she has no income.

On skill- $a$ labor market, only a fraction $L\left(a, w_{a}\right)$ of the $f(a)$ skill- $a$ individuals find a job. The function $L(.,$.$) summarizes all the ingredients of the labor demand behavior$ needed for our optimal tax theory. The matching unemployment theory of Mortensen and Pissarides (1999) and Pissarides (2000) provides micro-foundations for this function. Matching frictions imply that not all individuals find a job and not all firms find a worker. A zero-profit condition determines the number of vacancies created by firms, thereby the 
labor demand function $L(.,$.$) on each skill-specific labor market. Firms create vacancies$ until the cost of creating an additional vacancy is lower than the expected gain of filling it. As firms open more vacant jobs, congestion externalities decrease the probability for each vacancy to be filled, thereby the expected profit per vacancy. When wages decrease on skill- $a$ labor market, filling a job generates higher profits and firms create more vacancies. Lemma 1 in LPV shows that it is equivalent to specify a labor demand function $L(.,$.$) or$ to specify the underlying matching environment. Using this equivalence, we specify here the assumptions of the model in terms of the function $L(.,$.$) .$

Assumption $1 L(.,$.$) is defined for skill levels a \in\left[a_{0}, a_{1}\right]$ and for wages $w \in[0, a]$, takes values within $[0,1)$ and satisfies the following conditions:

i) $L(.,$.$) is decreasing in wages w$.

ii) $L(.,$.$) is increasing in skill a.$

iii) The wage elasticity $\partial \log L(a, w) / \partial \log w$ is decreasing in wages.

iv) The wage elasticity $\partial \log L(a, w) / \partial \log w$ is increasing in skill.

Part $i$ ) states that employment is decreasing in wages $w$. According to Part ii), more productive workers find a job more easily for a given wage level. Part iii) and iv) imply that employment is more sensitive to wage changes (in terms of elasticity) at high wages and at low productivity levels. These assumptions on $L(.,$.$) are not very restrictive and$ might seem quite natural. They allow a wide range of functions, for instance the linear employment function $L\left(a, w_{a}\right)=\frac{a-w_{a}}{a}$.

We next describe wage setting. On each skill-specific labor market, we assume that the wage maximizes the "wage-setting objective"

$$
\mathcal{U}(c, w, a) \stackrel{\text { def }}{\equiv} c \cdot L(a, w)
$$

Thus,

$$
w_{a}=\underset{w}{\arg \max } \quad(w-T(w)) \cdot L(a, w)
$$

The wage-setting objective $\mathcal{U}(., .,$.$) is skill-specific, increasing in disposable income c$ ( an employee's welfare depends positively on the after-tax wage) and decreasing in the pre-tax wage $w$ ( a higher pre-tax wage reduces firms' profit and thus labor demand). Various microfoundations can justify the functional specification of this wage-setting objective. As in Mirrlees, we focus on redistribution and consider a setting such that the role of taxation is only to redistribute income and not to restore efficiency (see section 3.3 and HL for a case where the no-tax economy is inefficient). To obtain this property, the matching literature typically assumes that wages are the outcome of a Nash bargain and that the workers' bargaining power satisfies the so-called Hosios (1990) condition.2 Alternatively,

\footnotetext{
${ }^{2}$ Under this condition, the bargaining power of workers equals the elasticity of the matching function with respect to the stock of unemployment.
} 
the Competitive Search Equilibrium of Moen (1997) leads also to 22 when search is directed by wages and by skill. Still another possibility is to assume that a skill-specific utilitarian monopoly union selects the wage $w_{a}$ before firms decide about vacancy creation (see Mortensen and Pissarides, 1999).

The first-order condition of (2) writes

$$
-\frac{\partial \log L}{\partial \log w}\left(a, w_{a}\right)=\eta\left(w_{a}\right)
$$

where

$$
\eta(w) \stackrel{\text { def }}{=} \frac{1-T^{\prime}(w)}{1-\frac{T(w)}{w}}=\frac{\partial \log (w-T(w))}{\partial \log w}
$$

When the pre-tax wage increases by one percent, the term $\partial \log L / \partial \log w$ measures the relative decrease in employment, while $\eta(w)$ measures the relative increase in disposable income. At equilibrium, Equation (3) requires that these two relative changes cancel each other out. The elasticity $\eta(w)$ of disposable income with respect to the pre-tax wage summarizes how the tax system affects the equilibrium wage.$^{3}$ A decrease in $\eta\left(w_{a}\right)$, either due to a higher marginal tax rate or to a lower average tax rate, induces that a given increase in the pre-tax wage leads to a smaller increase in disposable income. Higher employment probability is then substituted for lower disposable income in the wage-setting process and so the pre-tax wage decreases.

We finally describe the government's budget constraint. Each of the $L\left(a, w_{a}\right) \cdot f(a)$ employed workers of skill $a$ pays an amount $w_{a}-c_{a}$ of taxes. Let

$$
U_{a} \stackrel{\text { def }}{\equiv} \max _{w} \mathcal{U}(w-T(w), w, a) \equiv(w-T(w)) \cdot L(a, w)
$$

be the value of the maximized wage-setting objective for workers of skill $a$. Hence, $U_{a}=$ $c_{a} \cdot L\left(a, w_{a}\right)$ and the government's budget constraint ${ }^{4}$ writes

$$
\int_{a_{0}}^{a_{1}}\left[w_{a} \cdot L\left(a, w_{a}\right)-U_{a}\right] \cdot f(a) \cdot d a=0
$$

Given the unemployment uncertainty, individuals of skill $a$ get on average a pre-tax wage $w_{a} \cdot L\left(a, w_{a}\right)$ and an after-tax income $U_{a}$. Multiplying the difference between the two by the density of workers and taking the sum for all skill levels gives the government's aggregate revenue.

\section{II.2 Comparison with a Mirrleesian environment}

In the "frictional" environment described above, the pre-tax wage decreases with marginal tax rates. This is because the pre-tax wage maximizes a wage-setting objective that is increasing in disposable income $c$ and decreasing in pre-tax wage $w$. The same

\footnotetext{
${ }^{3} \eta(w)$ is the so-called Coefficient of Residual Income Progression.

${ }^{4}$ Introducing an exogenous amount of public expenditure does not change the qualitative results of the model.
} 
property holds in a "Mirrleesian" environment characterized by no frictions on the labor market, an infinitely elastic labor demand and labor supply responses along the intensive margin. In this classical framework, a higher pre-tax wage is due to more effort (less leisure). Conversely, a higher disposable income increases consumption and pushes up utility. Therefore, there exist specifications of individuals' preferences in the Mirrleesian environment that induce the same responses of pre-tax wages to taxation as our frictional environment. Let $h$ denote working time. An individual of skill $a$ working $h$ earns $w=a \cdot h$. Consider then preferences that are linear in consumption with a multiplicatively separable and skill-specific utility of leisure $v(.,$.$) . So, the utility function equals$

$$
c \cdot v(a, h)
$$

These preferences can be rewritten as a function of the observables $c$ and $w$ using $w=a \cdot h$ :

$$
\mathcal{U}^{M}(c, w, a) \stackrel{\text { def }}{\equiv} c \cdot L(a, w)
$$

where $L(a, w) \stackrel{\text { def }}{\equiv} v\left(a, \frac{w}{a}\right)$. Equations 11 and 7 have the same form but the economic interpretation of the function $L(.,$.$) is different. In the frictional environment, L(.,$. stands for the probability that an individual of skill $a$ is employed, whereas in the Mirrleesian environment it captures the utility of leisure. In both environments, equilibrium wages maximize $(w-T(w)) \cdot L(a, w)$, thereby generating identical responses of wages to taxation. The different economic interpretation of $L(.,$.$) has a crucial consequence: the$ deadweight losses of taxation are different. To understand this difference, define

$$
U_{a}^{M} \stackrel{\text { def }}{\equiv} \max _{w} \mathcal{U}^{M}(w-T(w), w, a)
$$

as the value of the wage-setting objective for workers of skill $a$ in the Mirrlesian environment. Hence, disposable income verifies $c_{a}=U_{a}^{M} / L\left(a, w_{a}\right)$. Each individual of skill $a$ pays taxes $w_{a}-\left(U_{a}^{M} / L\left(a, w_{a}\right)\right)$ and the government's budget constraint writes

$$
\int_{a_{0}}^{a_{1}}\left[w_{a}-\frac{U_{a}^{M}}{L\left(a, w_{a}\right)}\right] \cdot f(a) \cdot d a=0
$$

In this environment, deadweight losses are minimized whenever wages $w_{a}$ maximize tax revenues per individual of skill $a$ for a given value of the wage-setting objective. In the Mirrleesian environment, efficiency, i.e. the situation where deadweight losses are minimized, requires a zero marginal tax rate.$^{5}$

In the frictional environment, a change in wages affects the level of taxes paid by employed workers, $w_{a}-\frac{U_{a}}{L\left(a, w_{a}\right)}$, exactly as in the Mirrleesian environment. However, it also affects the fraction of taxpayers $L\left(a, w_{a}\right)$. Hence, expected tax revenues per individual of

\footnotetext{
${ }^{5}$ Formally, the first-order condition of maximizing $w_{a}-\frac{U_{a}}{L\left(a, w_{a}\right)}$ in $w_{a}$ for a given $U_{a}$ writes (using $\left.c_{a} / w_{a}=1-\left(T\left(w_{a}\right) / w_{a}\right)\right): \frac{1}{1-\frac{T}{w}}=-\frac{\partial \log L}{\partial \log w}\left(a, w_{a}\right)$, which implies $T^{\prime}\left(w_{a}\right)=0$, given 3 and 4 .
} 
skill $a$ equal $w_{a} L\left(a, w_{a}\right)-U_{a}$. So, the deadweight losses associated to taxation are minimized whenever the average pre-tax wage $w_{a} L\left(a, w_{a}\right)$ per individual of skill $a$ is maximized. Efficiency therefore requires that the elasticity $\eta\left(w_{a}\right)$ of disposable income with respect to wages is equal to 1 , that is the marginal tax rate is equal to the average tax rate (see Equation (4)). Consequently, when the average tax rate is positive (negative), the efficient level of the marginal tax rate is also positive (negative).

\section{II.3 Social optimum}

We henceforth only consider the frictional environment. The government is ready to compensate individuals for their innate heterogeneous ability. To formalize this idea, we consider a social objective which consists in an increasing and concave transformation of individuals' skill-specific expected utility $U_{a}$ :

$$
\Omega=\int_{a_{0}}^{a_{1}} \Phi\left(U_{a}\right) f(a) d a
$$

The government maximizes its objective subject to the budget constraint (6) and the choices made by the agents. The government does not observe the productivity of each job but only the wage negotiated by each worker-firm pair. Since a worker-firm pair maximizes the wage-setting objective $\mathcal{U}(c, w, a)$ that is increasing in $c$, one can apply the Mirrleesian methodology to solve the optimal tax problem.

The taxation principle (Hammond 1979, Rochet 1985 and Guesnerie 1995) applies. So, the set of allocations induced by a tax system $T$ (.) through the wage-setting equations (2) corresponds to the set of incentive-compatible allocations $\left\{w_{a}, c_{a}, U_{a}\right\}_{a \in\left[a_{0}, a_{1}\right]}$ that verify

$$
\forall(a, b) \in\left[a_{0}, a_{1}\right]^{2} \quad \mathcal{U}\left(c_{a}, w_{a}, a\right) \geq \mathcal{U}\left(c_{b}, w_{b}, a\right)
$$

This condition expresses that a worker-firm pair of type $a$ chooses the bundle $\left(w_{a}, c_{a}\right)$ designed for her, rather than any other bundle $\left(w_{b}, c_{b}\right)$ designed for worker-firm pairs of any other type $b$. From Assumption $1 i v$ ), the strict single-crossing condition holds. Hence, 9 is equivalent to the envelope condition associated to (2)

$$
\dot{U}_{a}=U_{a} \cdot \frac{\partial \log L}{\partial a}\left(a, w_{a}\right)
$$

and the monotonicity requirement that the wage $w_{a}$ is a nondecreasing function of the skill level $a$. We consider the so-called first-order approach that considers the "relaxed" problem without the monotonicity constraint ${ }^{6}$

Hence, the government's problem consists in finding an allocation $a \mapsto\left\{w_{a}, U_{a}\right\}$ that maximizes the social objective (8) subject to the government's budget constraint (6) and

\footnotetext{
${ }^{6}$ Simulations in HLPV and LPV verify that along the solutions of the relaxed problem, wages are non-decreasing in skills.
} 
the incentive constraint (10). Taking the wage as the control variable and the expected utility as the state variable 7 the optimal tax problem can be solved using the Hamiltonian

$$
\mathcal{H}(w, U, a, \lambda, q) \stackrel{\text { def }}{\equiv}\{\Phi(U)+\lambda[w \cdot L(a, w)-U]\} \cdot f(a)+q \cdot U \cdot \frac{\partial \log L}{\partial a}(a, w)
$$

where $\lambda$ is the multiplier associated to the government's budget constraint and $q$ is the co-state variable associated to the incentive constraint. It is convenient to use $Z_{a}=$ $-\left(q_{a} \cdot U_{a}\right) / \lambda$. Then the first-order conditions of the government's problem are 10$)$ and

$$
\begin{aligned}
\frac{\partial\left(w_{a} L\left(a, w_{a}\right)\right)}{\partial w} \cdot f(a) & =\frac{\partial^{2} \log L}{\partial a \partial w}\left(a, w_{a}\right) \cdot Z_{a} \\
-\dot{Z}_{a} & =\left(1-\frac{\Phi^{\prime}\left(U_{a}\right)}{\lambda}\right) \cdot U_{a} \cdot f(a) \\
Z_{a_{1}} & =0 \\
Z_{a_{0}} & =0
\end{aligned}
$$

Combining $11 \mathrm{~b}$ and $(11 \mathrm{c})$ gives

$$
Z_{a}=\int_{a}^{a_{1}}\left(1-\frac{\Phi^{\prime}\left(U_{t}\right)}{\lambda}\right) \cdot U_{t} \cdot f(t) \cdot d t
$$

These relations describe the equity-efficiency tradeoff faced by the government. To see the intuition behind this optimality condition, we focus on the optimization problem for agents of type $a$ and consider a marginal increase in their wage. The incentive constraint (10) implies that the value of the wage-setting objective for workers of skill $a, U_{a}$, is predetermined and not affected by the change in the wage $w_{a}$.

The left-hand side of Equation (11a) stands for the efficiency part of the trade-off. An increase in the wage rate $w_{a}$ decreases the probability of being employed, so the impact on the average pre-tax wage $w_{a} L\left(a, w_{a}\right)$ per individual of skill $a$ is ambiguous.

The right-hand side of Equation (11a) represents the impact on informational rents of a higher pre-tax wage for type- $a$ workers. When jobs of productivity $a$ are better paid (while keeping $U_{a}$ fixed), a wage-setter of type $t>a$ finds it profitable to choose the wage $w_{a}$ designed for type- $a$ jobs instead of the wage $w_{t}$ designed for her. To prevent this "mimicking", the value of the wage-setting objective for type-t jobs has to grow. Using Equation (10), the term in front of $Z_{a}$ on the right-hand side of 11a measures by how much the rate of change of the skill-specific value of the wage-setting objective $\dot{U}_{a} / U_{a}$ has to grow when $w_{a}$ marginally increases. From Assumption $1 \mathrm{iv}$ ), this term is positive.

The incentive-compatibility constraints will remain satisfied if all jobs with a productivity higher than $a$ benefit from an equivalent relative increase in their wage-setting objective. For any type $t$ above $a$, this relative increase times $U_{t}$ gives the rise in the wage-setting objective. Each unit of the latter generates an increase in the social welfare

\footnotetext{
${ }^{7}$ and making the regularity assumption that the control variable is continuous in skill
} 
measured by $\Phi_{t}^{\prime}$ and implies a budgetary cost equal to $\lambda$. Aggregating these two terms between $a$ and $a_{1}$ and dividing by the cost of public funds gives (12).

The intuition behind Equation $111 \mathrm{~d}$ ) is the following. A unit relative increase of the wage-setting objective spills over the whole skill distribution and its effect is proportional to $Z_{a_{0}}$. At the optimum, this change must have no first-order effect, so $Z_{a_{0}}$ has to equal zero.

We henceforth use the words "optimal - optimality" to characterize the solution to the government's problem. We get the following proposition:

Proposition 1 i) For each $a \in\left(a_{0}, a_{1}\right)$, optimal wages are below their efficient levels.

ii) Optimal and efficient wages coincide at both ends of the skill distribution.

Proof. By Assumption 1 ii) and Equation $10, U_{a}$ is increasing in $a$, and $1-\frac{\Phi^{\prime}\left(U_{a}\right)}{\lambda}$ is thus also increasing in $a$. Moreover, from Equations $(11 \mathrm{c})$ and $(11 \mathrm{~d})$, the mean value theorem ensures the existence of a critical skill level $\hat{a}$ such that $\dot{Z}_{\hat{a}}=0$, which by Equation $11 \mathrm{~b}$ implies that $1-\frac{\Phi^{\prime}\left(U_{\hat{a}}\right)}{\lambda}=0$. So, from $11 b$, Function $a \mapsto Z_{a}$ is increasing on $\left[a_{0}, \hat{a}\right]$ and decreasing on $\left[\hat{a}, a_{1}\right]$. It thus take positive values on $\left(a_{0}, a_{1}\right)$ and is nil at $a=a_{0}, a_{1}$. Using Equation (11a) and Assumption 1 iii) ends the proof.

The intuition of Proposition 1 is that the government wants to avoid informational rents, because those rents benefit to high-skilled jobs. Distorting wages below their efficient levels is the only way the government can do this. The optimum trades off the equity gains of reducing informational rents against the efficiency losses of distorting "optimal" wages below their "efficient"levels. At both ends of the skill distribution, the equity gain is null, so wages are not distorted. Proposition 1 implies the three following corollaries.

Corollary 1 i) For each $a \in\left(a_{0}, a_{1}\right)$, the optimal probability of being employed, $L\left(a, w_{a}\right)$, is above its efficient level.

ii) Optimal and efficient probabilities of being employed coincide at both ends of the skill distribution. Aggregate employment is above its efficient level.

This follows directly from Proposition 1] since the skill-specific employment probability is decreasing in the skill-specific wage (by Assumption $1 i$ ). Finally,

Corollary 2 The average tax rate is increasing along the whole wage distribution.

Proof. From the first-order condition (3) of the wage-setting program, the optimal allocation where wages are below their efficient value can only be decentralized by implementing a tax schedule such that the elasticity $\eta(w)$ of disposable income with respect to wages is below 1. From (4), this implies that for all wage levels (except for $w_{0}$ and $w_{1}$ ) the marginal 
tax rate $T^{\prime}(w)$ is above the average tax rate $T(w) / w$. Hence the optimal average tax rate is increasing in the wage.

In other words, the optimal allocation is implemented by a progressive (in the sense of increasing average tax rates) tax schedule because progressivity reduces wages below their efficient levels.

Corollary 3 If the skill distribution is bounded, the marginal tax rate is positive at the top.

Proof. According to Point ii) of Proposition 1, at the highest skill level, the optimal wage is efficient. So, from the first-order condition (3) of the wage-setting program one must have $\eta\left(w_{a_{1}}\right)=1$. From 4 , this implies that $T^{\prime}\left(w_{a_{1}}\right)=\frac{T\left(w_{a_{1}}\right)}{w_{a_{1}}}$. Theses rates are positive by the budget constraint (6) and Corollary 2 .

\section{Extensions}

This Section investigates to which extent our canonical model of optimal redistribution with endogenous unemployment is affected when some assumptions are relaxed. It builds on the results of HLPV, HL and LPV.

\section{III.1 Assistance benefits}

Our simple model postulates that the unemployed get no income. This assumption is not consistent with the fact that the government aims at redistributing to the poor. It is therefore necessary to introduce unemployment benefits. However, as the model is static, the government is unable to infer the type of a jobless individual from her past earnings. Thus, we focus on an assistance benefit, i.e. a benefit that is the same for unemployed agents, whatever their skill level. Although redistribution is made through a high assistance benefit and the surplus of workers is reduced, the results obtained in the previous section are still valid.

However, the invariance of the results can be explained by the fact that redistributing through a high assistance benefit has no efficiency effect since no participation decision is taken into account. HLPV consider an endogenous participation. For simplicity, they assume that all individuals face the same cost of participation, whatever their skill level. Consequently, every agent above (below) an endogenous threshold of skill participates (does not participate). Moreover, they assume that the government is unable to screen the search activities of the unemployed. Therefore, the government is constrained to give the same level of assistance benefit to all non-employed individuals, whatever their skill or their participation decisions. In this environment, HLPV show that for all participating types, point $i$ ) of Proposition 1 and of Corollary 1, and Corollary 2 still hold. Point ii) 
of Proposition 1 and of Corollary 1 do not hold anymore for the lowest skill $a_{0}$. This is because they do not participate anymore. The government chooses to reduce efficiency by pushing down participation because it allows her to reduce the informational rents given to the more productive worker-firm pairs. Moreover, in order to reduce participation, in-work benefits (if any) are lower than assistance benefits.

\section{III.2 The extensive margin of the labor supply}

As is shown in many empirical studies (e.g. Meghir and Phillips (2008)), labor supply is particularly responsive to taxation on its extensive margin (the decision to participate or not on the labor market). Moreover, theoretical papers have emphasized that in an optimal redistribution framework without (involuntary) unemployment, the tax schedule properties are crucially affected by the introduction of an endogenous extensive margin (Diamond (1980), Saez (2002) and Choné and Laroque (2005)).

The inclusion of participation responses in HLPV is not satisfying since the elasticity of participation is infinite at a threshold skill and zero above. Assuming that the cost of participation varies both within and between skill levels, LPV provide a much more general treatment of participation. In the classical theory of unemployment 8 the employment level is solely determined by labor demand, an unrealistic property according to empirical findings. Conversely, in LPV, both labor supply and labor demand determine the equilibrium level of employment through the matching function. LPV show that point $i$ ) of Proposition 1 and of Corollary 1 and Corollary 2 hold if the government has a Maximin objective and the elasticity of participation decreases in skill (the most plausible case according to empirical evidences, see Juhn et alii (1991), Immervoll et alii (2007) or Meghir and Phillips (2008)). If the government has a more general social objective, no analytical result can be put forward. However, LPV suggest that points $i$ ) of Proposition 1 and of Corollary 1 still hold. The most important difference with the results of HLPV under a general social objective concerns participation and the tax schedule. While HLPV show that marginal tax rates are positive everywhere and a higher transfer to low-skilled workers than to the non-employed is never optimal (no EITC), a more general treatment of participation decisions appears to be compatible with negative marginal rates and an EITC for the low skilled. Thus, upward distortions of the low skilled individuals' participation rates can be optimal.

\section{III.3 Inefficiency of the no-tax economy}

In order to focus on redistributive issues, our canonical model assumes that the no-tax economy is efficient. However, this is a very special case since there is no reason to

\footnotetext{
${ }^{8}$ Which consists in standard labor-supply and labor demand curves and a wage above the marketclearing level.
} 
believe that a decentralized wage setting necessarily maximizes efficiency. HL build on the framework of HLPV but they do not assume that the Hosios condition is satisfied. In the case where the bargaining power of workers is too low, they show that bunching at the bottom of the wage distribution is optimal. This situation suggests that a binding minimum wage can be optimal.

\section{III.4 Redistribution within skill groups}

Unemployment raises an issue that does not appear in a Mirrleesian framework: the redistribution between employed and unemployed individuals endowed with the same skill. For simplicity, HLPV neglect this issue by considering an ex-ante social objective that depends on individuals' expected utility:

$$
\int_{a_{0}}^{a_{1}} \Phi\left(\left(w_{a}-T\left(w_{a}\right)\right) \cdot L\left(a, w_{a}\right)+b \cdot\left(1-L\left(a, w_{a}\right)\right)\right) \cdot f(a) \cdot d a
$$

where $b$ stands for the welfare benefit. Conversely, one can adopt the ex-post objective that depends on realized incomes:

$$
\int_{a_{0}}^{a_{1}}\left\{L\left(a, w_{a}\right) \cdot \Phi\left(w_{a}-T\left(w_{a}\right)\right)+\left(1-L\left(a, w_{a}\right)\right) \cdot \Phi(b)\right\} \cdot f(a) \cdot d a
$$

LPV explains that the adoption of the ex-post objective provides an additional motivation to distort wages downwards: a lower wage reduces the income inequality between employed and unemployed individuals of the same skill and increases the number of employed.

\section{III.5 Further research}

Finally, we list some potential extensions. First, a dynamic model would enable to introduce earning-related unemployment insurance. Hence, one can expect that a "dynamic optimal taxation" version (à la Golosov et alii 2003) of this kind of model would deliver interesting insights about the optimal combination of unemployment insurance and taxation to redistribute income. Second, we have implicitly considered that it is impossible for the government to monitor job-search activity. This is clearly a strong assumption that should be relaxed. Third, we abstract from any response of labor supply along the intensive margin. Although the responses along the extensive margin seem empirically much more important, enriching the framework to include hours of work, in-work effort or educational investment would be interesting. Finally, labor supply decisions are often taken at the household level, not at the individual level (see Kleven et alii 2009). An optimal redistributive theory incorporating this issue would thus be more comprehensive.

\section{References}

[1] Boone, J. and L. Bovenberg, 2004, The Optimal Taxation of Unskilled Labor with Job Search and Social Assistance, Journal of Public Economics, 88(11), 2227-2258. 
[2] Choné, P. and G. Laroque, 2005, Optimal Incentives for Labor force participation, Journal of Public Economics, 89(2-3), 395-425.

[3] Daveri F. and G. Tabellini, 2000, Unemployment, Growth and Taxation in Industrial Countries, Economic Policy, 15(30), 49-104.

[4] Diamond, P., 1980, Income Taxation with fixed hours of work, Journal of Public Economics, 13(1), 101-110.

[5] Engström, P., 2009, Unemployment benefits as a means for optimal redistribution, Finanzarchiv, 65(1), 21-36.

[6] Golosov, M., N. Kocherlakota and A. Tsyvinski, 2003, Optimal Indirect and Capital Taxation, Review of Economic Studies, 70(3), 569-547.

[7] Guesnerie, R., 1995, A Contribution to the Pure Theory of Taxation, Cambridge University Press.

[8] Hammond, P., 1979, Straightforward Individual Incentive Compatibility in Large Economies, Review of Economic Studies, 46(2), 263-282.

[9] Hersoug, T., 1984, Union Wage Responses to Tax Changes, Oxford Economic Papers, 36(1), 37-51.

[10] Hosios, A., 1990, On the Efficiency of Matching and Related Models of Search and Unemployment, Review of Economic Studies, 57(2), 279-298.

[11] Hungerbühler, M., E. Lehmann, 2009, On the Optimality of a Minimum Wage: New Insights from Optimal Tax Theory, Journal of Public Economics, 93(3-4), 464-481.

[12] Hungerbühler, M., E. Lehmann, A. Parmentier and B. Van der Linden, 2006, Optimal Redistributive Taxation in a Search Equilibrium Model, Review of Economic Studies, 73(3), 743-767.

[13] Immervoll, H., Kleven, H., Kreiner, C. T. and Saez, E., 2007, Welfare reforms in European countries: a Microsimulation analysis, Economic Journal, 117(516), 1-44.

[14] Juhn, C., Murphy K. M.,Topel R. H., Yellen J. L. and Baily M. N., 1991, Why has the Natural Rate of Unemployment Increased over Time?, Brookings Papers on Economic Activity, 1991(2), 75-142.

[15] Kleven, H. J., C. T. Kreiner, E. Saez, 2009, The Optimal Income Taxation of Couples, Econometrica, $\mathbf{7 7}(2), 537-60$.

[16] Lehmann, E., A. Parmentier and B. Van der Linden, 2009, Optimal income taxation with endogenous participation and search unemployment, CREST working paper 2009-01.

[17] Lockwood B. and Manning A., 1993, Wage Setting and the Tax System: Theory and evidences for the United Kingdom, Journal of Public Economics, 52(1), 1-29.

[18] Manning, A., 1993, Wage Bargaining and the Phillips Curve: The Identification and Specification of Aggregate Wage Equations, Economic Journal, 103(416), 98-118. 
[19] Meghir C. and D. Phillips, 2008, Labour Supply and Taxes, IZA discussion paper 3405.

[20] Moen, E., 1997, Competitive Search Equilibrium, Journal of Political Economy, 105(2), 385-411.

[21] Mirrlees, J., 1971, An Exploration in the Theory of Optimum Income Taxation, Review of Economic Studies, 38(2), 175-208.

[22] Mortensen, D. and Pissarides, C., 1999, New developments in models of search in the Labor Market, in O. Ashenfelter and D. Card (eds.), Handbook of Labor Economics, vol 3 B, North-Holland, Amsterdam.

[23] Nickell, S., W. Ochel and L. Nunziata, 2005, Unemployment in the OECD since the 1960s. What do we know?, Economic Journal, 115(500), 1-27.

[24] Pisauro, G., 1991, The effect of taxes on labour in efficiency wage models, Journal of Public Economics, 46(3), 329-345.

[25] Pissarides, C. A., 1998, The impact of employment tax cuts on unemployment and wages: the role of unemployment benefits and tax structure, European Economic Review, 42(1), 155-183.

[26] Pissarides, C. A., 2000, Equilibrium Unemployment Theory, Second Edition, MIT Press, Cambridge, USA.

[27] E. C. Prescott, 2004, Why Do Americans Work So Much More Than Europeans?, Federal Reserve Bank of Minneapolis Quarterly Review, 28(1), 2-13.

[28] Rochet, J-C, 1985, The taxation principle and multi-time Hamilton-Jacobi Equations, Journal of Mathematical Economics, 14(2), 113-28.

[29] Røed, K., S. Strøm, 2002, Progressive Taxes and the Labour Market: Is the Tradeoff Between Equality and Efficiency Inevitable?, Journal of Economic Surveys, 16(1), $77-110$.

[30] R. Rogerson, 2006, Understanding Differences in Hours Worked, Review of Economic Dynamics, 9(3), 365-409.

[31] Saez, E., 2002, Optimal Income Transfer Programs:Intensive Versus Extensive Labor Supply Responses, Quarterly Journal of Economics, 117(3), 1039-1073.

[32] Saez, E., J. Slemrod and S. Giertz, 2009, The Elasticity of Taxable Income with Respect to Marginal Tax Rates: A Critical Review, NBER Working Paper 15012.

[33] Sørensen, P. B., 1997, Public finance solutions to the European unemployment problem?, Economic Policy, 12(25), 223-264.

[34] Stiglitz, J., 1982, Self-Selection and Pareto Efficient Taxation, Journal of Public Economics, 17(2), 213-240. 